\title{
Desigualdade social na escola
}

\author{
Social inequality in school
}

\author{
Viviane Lima da CONCEIÇÃO' \\ Maria Helena Rodrigues Navas ZAMORA²
}

\begin{abstract}
Resumo
Considerando o contexto brasileiro de ampla desigualdade social, o objetivo central desta pesquisa foi investigar como tal dado impacta na permanência escolar de estudantes, em sua maioria de origem popular, em uma escola federal de ensino médio/técnico da cidade do Rio de Janeiro. Os referenciais teóricos utilizados foram o da Psicologia da Libertação, da Psicologia Socio-histórica e da Análise Institucional. Foram investigadas as condições de permanência de estudantes de classes populares do ensino médio técnico. Foi realizada uma pesquisa-ação, com questionário, grupo focal e observação participante com estudantes. Foi dada atenção às diversas informações obtidas quanto aos enfrentamentos cotidianos vividos pelos estudantes. A partir da análise de conteúdo, os resultados revelaram que os participantes reconhecem a existência de dificuldades, das mais diversas ordens, sendo as mais mencionadas, o cansaço e a distância entre a residência e a escola, além de problemas de aprendizagem, que podem causar entraves à permanência dos alunos. O estudo pretende desvelar a lógica da instituição bem como reafirmar a importância de pensar a partir da realidade e do cotidiano dos estudantes para formular políticas institucionais de apoio que realmente defendam uma educação pública e de qualidade ao alcance de todos.
\end{abstract}

Palavras-chave: Adolescente; Ensino; Iniquidade social; Psicologia social.

\begin{abstract}
Taking into consideration the Brazilian context of wide social inequality, the primary objective of this research was to investigate how social inequality impacts the maintenance of attendance of low-income students (majority) in a public vocational-technical high school in Rio de Janeiro. The concepts of psychology of freedom, social-historical psychology, and institutional analysis were used. An action research was conducted using a structured interview, a focus group, and participant observation of students. All information gathered about the everyday struggles faced by the students was taken into account. The results revealed that the participants acknowledge the existence of varied difficulties, and the most frequently mentioned were fatigue, distance between school and home, and learning issues, which can affect the maintenance of attendance of students in schools. This study aims to show the inner functioning of institutional logic and reaffirm the importance of considering and focusing on the reality of students' everyday life to develop public policies to support and provide quality public education for all.
\end{abstract}

Keywords: Adolescent; Teaching; Social inequity; Social psychology.

\footnotetext{
$\nabla \nabla \nabla$

1 Centro Federal de Educação Tecnológica Celso Suckow da Fonseca. Av. Maracanã, 229, 20271-110, Rio de Janeiro, RJ, Brasil. Correspondência para/Correspondence to: V.L. CONCEIÇÃO. E-mail: <vivilyma@yahoo.com.br>.

2 Pontifícia Universidade Católica do Rio de Janeiro, Departamento de Psicologia, Programa de Pós-Graduação em Psicologia. Rio de Janeiro, RJ, Brasil.

Artigo baseado na dissertação de V.L. CONCEIÇÃO, intitulada "Psicologia, desigualdade e permanência de alunos em escola profissional técnica de nível médio". Universidade Salgado de Oliveira, 2012
} 
Este artigo resume uma pesquisa feita entre 2011 e 2012 (Conceição, 2012), cujo objetivo central foi investigar como a desigualdade social impacta na permanência escolar de estudantes, em sua maioria de origem popular, em uma escola federal de ensino médio/técnico da cidade do Rio de Janeiro. A instituição será chamada aqui de "Escola Federal de Ensino Médio/Técnico" ou, simplesmente, EFEMET. O interesse no estudo nasceu da vivência de uma das pesquisadoras, que atua como orientadora educacional no estabelecimento de ensino.

O trabalho tem como apoios teóricos a Psicologia da Libertação, de Martín-Baró, a Análise Institucional e Educação para a Autonomia, de Paulo Freire. As mediações teóricas provêm de uma vertente da Psicologia Social que "analisa a relação entre subjetividade e desigualdade, procurando romper a dualidade sócio/singular" (Sawaia, 2009, p.365).

A desigualdade social é um fenômeno histórico e possível de ser revertido. Suas várias formas (de classe, racial, sexo etc.) "são diferenças hierárquicas evitáveis e moralmente injustificadas ... . A desigualdade é uma violação aos direitos humanos" (Therborn, 2010, p.2). As relações sociais, em tal contexto, são permeadas por relações de dominação de classes sociais (Lopes et al., 2008).

A Organização das Nações Unidas (ONU) apontou, nos resultados da pesquisa do Índice de Desenvolvimento Humano (IDH) de 2011, realizado com 187 países, que o Brasil ficou na 84a posição (Programa das Nações Unidas para o Desenvolvimento, 2011). Neste cálculo são considerados três aspectos: conhecimento (educação), saúde e padrão de vida digno (indicado pela renda). O Brasil é, portanto, um dos países mais desiguais do mundo, considerado de baixa mobilidade social e educacional entre gerações. Apesar da redução dos níveis de pobreza extrema nos últimos anos, ainda é grande a distância entre as camadas sociais mais abastadas e o contingente populacional que vive à margem da sociedade, sem acesso aos direitos humanos mais básicos.

Muitos autores das Ciências Humanas, a partir da década de 1990, utilizam o conceito de exclu- são social para falar das múltiplas formas como as pessoas são "desprovidas de seus direitos básicos ... bem como do enfraquecimento ou a ruptura dos laços sociais ... e/ou a condição a que ele chega após tal ruptura" (Leal, 2009, p.261). A exclusão social caracteriza-se como um processo complexo e multifacetado, resultando no que vários autores vão chamar de desqualificação social, desfiliação, desagregação identitária, desumanização do outro, inclusão por exclusão, apartação social (Buarque, 1999; Castel, 1998; Guzzo \& Lacerda Jr., 2009; Guzzo, Mezzalira, Moreira, Tizzei, \& Silva Neto, 2010; Lavrador, 2005; Martín-Baró, 1986; 2003; Patto, 1999; Sawaia, 2009; Sung, 2002).

Diversas categorias de indivíduos encontram-se, por vários fatores, compreendidos como excluídos: idosos, homossexuais, mulheres, pessoas com deficiências, índios, população de rua etc. É inegável que os processos de segregação desumanizam esses "desfiliados" (Castel, 1998) e que as camadas segregadas tornam-se invisíveis para a sociedade (Costa, 2008; Gentile, 2003) e/ou são percebidas como inferiores e como objetos de temor. Contudo, pode-se entender que um conceito o qual aborda tantos grupos sociais e tantos fenômenos diferentes é demasiado abrangente e precisa ser utilizado de forma crítica (Castel, 1998; Lavrador, 2005; Leal, 2009). O conceito de desigualdade social é aqui utilizado por marcar o caráter concreto, histórico e estrutural das sociedades capitalistas contemporâneas. Isso não significa deixar de considerar os autores citados, mas articular analiticamente os conceitos de desigualdade e exclusão.

Se a educação é importante para dimensionar a desigualdade, é também importante entender que ela se encontra atravessada pela ideologia neoliberal, que deposita no indivíduo a capacidade de romper os limites e dificuldades (Gracindo, Marques, \& Paiva, 2005). Com isso, a educação acaba por implementar mecanismos que estimulam a competição e o desempenho meritocrático, sem se preocupar com as condições em que a competição é estabelecida.

Apesar da dificuldade do acesso à educação ser um dos fatores que mais contribuem para a manutenção da inequidade, rejeitam-se medidas que 
poderiam minorá-la e a educação passa a se constituir como um dos instrumentos de dominação (Penteado \& Guzzo, 2010). Neves (2005) compreende que os sistemas educacionais "vêm desenvolvendo mecanismos de filtragem social" e "terminam por privilegiar o acesso e permanência no sistema escolar dos representantes da classe dominante e seus aliados" (p.24). Contudo, no Brasil, apesar da atual tendência liberalizante, alguns instrumentos legais importantes defendem o direito à educação pública.

É no embate de forças que aumentam a desigualdade e na resistência a elas que os rumos da educação acabam por serem traçados. O exame de um caso concreto onde incidem essas forças, bem como outros fatores, põe em relevo práticas concretas da dimensão institucional, que podem influenciar tanto na permanência quanto na evasão, ou mesmo no abandono da escola pelos alunos (Mendes, 2013).

\section{Psicologia Social e a educação desigual}

A escola é um dos primeiros espaços de socialização e construção do conhecimento. Espera-se que ela propicie um ambiente de convivência acolhedor, livre de violência e um saber interessante. Todavia, ainda hoje, falta a muitas delas uma educação que leve em consideração as diferenças entre seus componentes: a diversidade cultural, a condição social, as possibilidades de cada um e as visões de mundo (Campos, 2003; Frigotto, 1993).

A Psicologia Social tem provocado questionamentos coletivos, implicando os agentes da educação, família e sociedade acerca do papel da escola e das políticas públicas na educação (Ramos, Rocha, Pimenta, \& Breia, 2004). Também tem cooperado na formulação e implementação das políticas públicas, compreendendo aspectos subjetivos que são fundados no processo social (Gonçalves, 2010), para que efetivamente garantam direitos humanos.

Examinando a atuação da Psicologia na escola, observa-se que ela pode ser uma prática que procura conciliar a escola com os alunos mais "difíceis", mas mantendo o centro do possível conflito no indivíduo. O pedido da instituição tem sido comumente a resolução de problemas de aprendizagem ou de disciplina (Pinho, Ribeiro, \& Souza, 2009) de alguns, terminando por isolar e patologizar (ou mesmo expulsar) determinados alunos e suas famílias, não raro os mais pobres ou com problemas específicos. Uma Psicologia que se retrate apenas como neutra e técnica pode tratar dessa maneira questões que de fato estão mais relacionadas ao quadro das desigualdades.

Para Martin-Baró (1986), a estrutura social capitalista é organizada de forma a sustentar a maior de todas as violências: a divisão de classes, que é estrutural. É parte dessa violência de dominação revestir-se de um caráter benéfico, ilusório, para que os dominados a percebam como um estado natural na sociedade e não percebam sua feição opressora. Para o autor, não se pode desvincular o estudo da violência da profunda compreensão da violência estrutural. O psicólogo social deve trabalhar para a conscientização e para alimentar a autonomia nos coletivos, refletindo sobre o cotidiano da instituição escolar, por exemplo, sempre considerando as condições de vida dos alunos.

Para a Análise Institucional, as instituições e seus agentes, desempenham práticas que muitas vezes reforçam uma forma de funcionar a serviço da manutenção de processos de exploração, dominação e mistificação (Baremblitt, 2002). Por exemplo, o sistema educacional acaba por produzir e reproduzir a alienação que propicia a disciplinarização dos indivíduos. A escola também ensina a obedecer e utiliza para isso um sistema de recompensas e penalidades, reproduzindo as desigualdades (Guzzo \& Euzébios, 2005; Penteado \& Guzzo, 2010).

Entretanto, é ainda Baremblitt (2002) quem dá outra possibilidade de instituição escolar, quando afirma que "uma escola também é um lugar onde se pode aprender a lutar pelos direitos; ... também é um lugar onde se pode integrar um sistema de ajuda mútua entre os alunos" (p.32). Os agentes escolares podem orientar seus alunos a reagir a processos opressivos, transformando a escola em 
um coletivo, onde estes possam se articular para o exercício da cidadania e da solidariedade.

Para Freire (1996), há necessidade de reflexão crítica sobre a prática docente, que deve envolver um processo dialético e dinâmico entre o fazer e o pensar, entre educador e educando. É preciso levar em consideração o reconhecimento da identidade cultural do aluno. A formação docente deve fazer-se com a observação da sensibilidade, emoções e dos pequenos gestos do cotidiano. Se é verdade que, "do ponto de vista dos interesses dominantes ... a educação deve ser uma prática imobilizadora e ocultadora de verdades" (p.99), somente o processo de conscientização pode desvelar a realidade opressiva e culminar na ação transformadora, em um segundo momento.

\section{A instituição pesquisada}

A Escola Federal de Ensino Médio/Técnico (EFEMET) foi criada em 1917 e oferece educação profissional técnica de nível médio e superior, incluindo pós-graduação, em várias modalidades e com várias sedes em outros municípios do estado. Quanto ao acesso às vagas, este se dá através de seleção por concurso público e convênio com escolas da rede pública. O concurso procura ser uma entrada democrática, mas submete às mesmas provas indivíduos de diferentes grupos sociais, culturas diversas e com formações escolares discrepantes. Desta maneira, pode se formar uma barreira aos estudantes das classes populares e o concurso pode operar como um mecanismo de exclusão.

Para incentivar a permanência, entre outras estratégias, a instituição concede uma bolsa auxílio alimentação, que tem como objetivo facilitar a permanência dos alunos em condição de vulnerabilidade social e econômica. A instituição tem, matriculados no ensino médio, 1598 alunos. No ano de 2011, segundo dados do próprio EFEMET, foram ofertadas 171 bolsas de auxílio alimentação com valor individual inferior a um terço do salário mínimo, para serem distribuídas entre a escola sede e outras unidades. Houve um total de 360 alunos concorrendo para obtenção do auxílio.

\section{Método}

A pesquisa-ação procura, de maneira geral, "um agir comunicativo, pautado pela ética emancipatória neste contexto, com intuito de transformá-lo a partir do entendimento entre os sujeitos envolvidos no processo investigativo sobre os problemas encontrados e suas possíveis soluções" (Neves, 2006, p.15). Seus objetivos são produzir conhecimentos pertinentes com a implicação dos envolvidos, enfatizando a descrição, a caracterização e compreensão do que se quer entender e transformar (Mayorga, Pereira, \& Rasera, 2009; Thiollent, 2000). Para Rocha \& Aguiar (2003), seus resultados "estão vinculados à tomada de consciência dos fatores envolvidos nas situações de vida imediata e na participação coletiva para a mudança da ordem social" (p.60).

Estão apresentadas estratégias metodológicas para acessar os embates entre forças latentes no universo aparentemente uniforme das instituições (Lapassade, 2006). São forças conservadoras (o instituído) e criativas (o instituinte) para Baremblitt (2002). A pesquisa pode ser um dispositivo, um "agitador", para que analisadores possam emergir (Baremblitt, 2002; Lourau, 1993). Analisador é um acontecimento revelador do funcionamento da lógica da instituição, um provocador de rupturas nas relações burocráticas e previsíveis.

\section{Participantes}

O total de participantes (respondentes aos instrumentos) foi de 19 alunos, os quais constituíram uma amostra de conveniência, de ambos os sexos e de várias séries. Todos os participantes assinaram o Termo de Consentimento Livre e Esclarecido antes de sua inclusão na amostra. O projeto de pesquisa foi aprovado pelo Comitê de Ética em Pesquisa da Universidade Salgado de Oliveira, Protocolo n 108/ 2011, em 15 de agosto de 2011. Todos os nomes próprios mencionados são fictícios.

Responderam ao questionário 12 alunos no total. Estes foram divididos em dois grupos: os que recebiam bolsa auxílio alimentação e os que não a recebiam, a fim de verificar se esse pertencimento 
produzia diferenças entre os discursos. Dos bolsistas, cinco eram do sexo masculino. Apenas um deles cursou todo o ensino fundamental em escola pública. Em relação às idades, todos tinham entre 16 e 18 anos e pertenciam às três séries do ensino médio. Do total de alunos que não recebiam bolsa, cinco eram do sexo masculino. Dois deles cursaram todo o fundamental em escola pública. As idades e escolaridade são similares às do grupo bolsista.

Do grupo focal participaram sete alunos, sendo que cinco recebiam o auxílio. Dentre os alunos, quatro eram do sexo feminino. Estiveram presentes dois alunos do primeiro ano e os demais cursavam o segundo ano. Não foram levantados outros dados. Excetuando-se o momento do questionário, não notamos maiores diferenças entre as respostas de bolsistas e não bolsistas e, por essa razão, esses dados não foram mais trabalhados. Quanto à observação participante, não é possível saber exatamente o número de alunos ou suas características. Em uma estimativa, cerca de noventa alunos, de ambos os sexos, das faixas etárias e escolaridade já mencionadas, ao longo de um ano.

\section{Instrumentos}

No questionário foram elaboradas doze questões sobre possíveis melhorias para o ambiente escolar, relacionamento com os colegas de classe e com os professores e dificuldades enfrentadas para o ingresso e para a permanência na instituição. Havia também sete questões abertas em forma de perguntas. Para a obtenção de respostas mais aprofundadas, bem como para observar a interação com o tema, foi realizado o grupo focal, o qual foi gravado em áudio e depois transcrito. Quanto à observação participante, foram organizados relatos sistemáticos de observação (diários de campo), coletados entre 2011 e 2012.

\section{Procedimentos}

O questionário poderia ser levado pelo aluno, e deveria ser devolvido em até uma semana ou ser entregue de imediato. Ao comparar as respostas dos bolsistas e não bolsistas, foi observado que os primeiros apresentaram respostas vagas e muito curtas. Isso talvez possa ser explicado pelo fato de ter sido pedida identificação dos alunos, bem como pela atividade ter sido supervisionada por uma funcionária do local, uma das pesquisadoras. É possível que o fato de receberem a bolsa (e temerem represálias) tenha reduzido a manifestação do pensamento crítico destes. Portanto, o questionário foi abandonado em favor do grupo focal, para favorecer a emergência da livre palavra. O grupo focal foi realizado durante o intervalo de almoço. Durou cerca de 50 minutos e todos demonstraram receio em atrasar-se para as aulas da tarde. Não foi possível realizar outros encontros por falta de tempo dos alunos.

A observação foi realizada nos horários de entrada e saída, no portão da EFEMET e adjacências, bem como na hora do almoço. Os alunos não têm espaços próprios, mas são autorizados a esquentar suas refeições em uma sala em comum com alguns técnicos e professores. Ali também podiam fazer suas refeições, mas devido ao pouco espaço, costumavam fazê-lo em outros lugares, em pé ou sentados no chão.

Foi escolhida a análise de conteúdo para interpretação dos dados de acordo com Bardin (2006). Para Chizzotti (2006), seu objetivo é "compreender criticamente o sentido das comunicações, seu conteúdo manifesto ou latente, as significações explícitas ou ocultas" (p.98).

A partir dos dados produzidos, foram levantadas as categorias: "Permanência", dividida, por sua vez, em duas subcategorias: "pontos positivos" - aspectos que podem incentivar a permanência dos alunos na EFEMET -, e "pontos negativos" - aspectos que deveriam ser melhorados para manter os alunos na instituição; e "Apoio", no qual os alunos sugerem práticas institucionais que poderiam favorecê-los em seu cotidiano.

\section{Resultados}

\section{Permanência}

Quanto aos pontos positivos de se estudar na EFEMET, os estudantes responderam: bom 
ensino, escola bem conceituada, possibilidade de uma vida melhor, relacionamento com pessoas de diferentes lugares, boa infraestrutura e bons professores, crescimento pessoal e maturidade, oportunidade de ingressar no mercado de trabalho com a ajuda do diploma do curso técnico. Já com relação aos pontos negativos, todos responderam que era a grande distância entre casa e escola e o tempo, que sentem como perdido, neste trajeto. Os alunos ressaltaram que se sentem cansados e que o fato de passarem o dia inteiro na escola torna seu cotidiano "muito estressante".

Além disso, foram apontados como negativos: burocracia, falta de vocação e/ou informação sobre o curso escolhido, falta de acompanhamento psicológico, de alguns professores, de local para tirar cópias, ausência de refeitório, falta de poder aquisitivo por parte dos alunos, dificuldades para acompanhar a didática de alguns professores e, em algumas disciplinas, pouca monitoria e aulas de reforço e dificuldade de acompanhar os estudos devido ao cansaço diante da extensa carga horária.

\section{Apoio}

Quando perguntados sobre possíveis mecanismos de apoio seguiram-se as sugestões: auxílio transporte, instalação de um refeitório, ter ar condicionado em todas as salas, ter água gelada nos bebedouros e melhor acomodação para o descanso. E ainda: melhor comunicação entre professores, funcionários e alunos e necessidade de criação de um espaço de convivência para os alunos. Também apareceu a crítica à falta de participação e autonomia e à burocracia:

Eu diria que é um colégio para professores, e não para alunos, pois estes praticamente não se beneficiam. Diria também que esta nossa instituição federal, é literalmente um "mini-Brasil". Voltando ao caso da burocracia, darei um exemplo, um aluno, ao pedir segunda via de uma carteirinha estudantil, ou até mesmo se quiser resolver um problema, será jogado para diversos departamentos diferentes, num interminável empurra-empurra (Debora, questionário).
Há outro aluno que manifesta sua descrença não só na possibilidade de mudanças na lógica institucional, como em simplesmente ser considerado participante da comunidade escolar:

Deixo aqui minhas opiniões, que provavelmente, não serão consideradas, assim como quaisquer outras sugestões já dadas anteriormente por uma grande parte dos alunos. Nunca seremos ouvidos! (Carlos, questionário).

Quando perguntados sobre as dificuldades encontradas diariamente, a maioria relatou levar mais de uma hora no percurso entre a residência e a escola. Vários contaram com detalhes sobre essa viagem, relatada como extenuante. Um dos alunos, morador de um bairro próximo, disse que "dependendo do engarrafamento, fico em torno de cinquenta minutos no ônibus até chegar em casa" (Paulo, grupo focal). Outro rapaz, que vem de outra cidade e sai de madrugada, chega antes das seis. Como tantos outros, aguarda de pé na rua, pois o portão só é aberto a partir das 6:30h.

Outra circunstância citada é a falta de recursos para a compra dos materiais escolares, que não são poucos. Deram como exemplo o fato de precisarem comprar um ou dois uniformes, além de outro específico para a educação física. A dificuldade para comprar o material do curso técnico também foi mencionada, sendo que alguns acabam por reutilizar o material de um colega ou irmão do período anterior e outros pedem emprestado.

Tem sido um problema para os mais pobres o fato de que o cartão de passagem de gratuidade de estudantes oferece, apenas, uma passagem de ida e outra de volta. Aqueles que utilizam mais de uma condução precisam completar a passagem com dinheiro: "No fim do mês fica mais apertado" (Jorge, questionário).

Quando perguntados sobre sugestões para melhorar a rotina, os participantes concordaram que seria bom ter uma carga horária menor. Há cursos com aulas das $7 \mathrm{~h}$ às $18 \mathrm{~h}$. Não tendo tempo de estudar no contraturno, alguns disseram fazê-lo no ônibus. Já os alunos que moram mais longe, mencionaram que seria interessante se houvesse um 
dormitório: "Pego ônibus e trem, normalmente venho e volto em pé, não dá pra cochilar" (Selma, grupo focal).

No grupo focal, os participantes relataram que seria importante a instalação de um restaurante na instituição, pois, mesmo aqueles com bolsa de estudos constataram que o dinheiro não é suficiente para todo o mês:

Tomo café às cinco da manhã, pra estar na escola as sete, quando dá nove horas já estou com fome, aí compro um salgado. Às treze horas, almoço e quando dá dezesseis horas, preciso comer algo, pois só chego em casa às vinte horas ou mais tarde, depende do transporte. Outras escolas têm bandejão, por que nós não temos? (Olga, grupo focal).

Não há quase nenhum tempo disponível. O intervalo entre as aulas é de quinze minutos e não há outra pausa. Então correm para o banheiro, apressam-se a beber água e ingerem, como observado, uma comida hipercalórica, com excesso de sal e gordura, quando comem.

Entre os pontos negativos, o mais relevante é o pouco tempo reservado para o descanso. Em média, os alunos participantes relataram dormir cerca de cinco horas por noite. "No período de prova é pior, pois ficamos até de madrugada estudando. Parecemos uns zumbis" (Hugo, grupo focal), e ainda: "estudamos nos finais de semana ou até tarde da noite" (Fátima, grupo focal). Outro aluno relatou uma rotina de estudos quase sem pausa: "eu saio da aula da disciplina em que tive uma boa média e fico estudando para a matéria que tenho dificuldade... muitos alunos fazem isso" (Felipe, grupo focal).

\section{Discussão}

Martín-Baró (1986) recomenda que qualquer intervenção parta do conhecimento da realidade concreta do povo, de seus sofrimentos, aspirações e lutas. Eis porque foram preservadas algumas de suas falas, bem como as observações cotidianas dos autores a respeito daqueles que, em um primeiro olhar, parecem apenas alunos jovens e bem ajustados em uma escola acessível e de bom padrão.
A instituição em questão não parece ter a prática de ouvir o corpo discente nem procurar conhecer suas condições concretas de existência. Aparentemente, não leva em consideração a desigualdade social nem a relação desta com a educação (Guzzo \& Euzébios, 2005). Disso resulta que as decisões importantes para a vida dos alunos não são tomadas com sua participação.

Os estudantes gostam da oportunidade de aprender com professores de bom nível acadêmico, de usufruir de boas instalações, de fazer novas amizades, mas ressaltaram os esforços desmesurados que essa jornada dupla (ou mesmo tripla) demanda. Em qualquer caso, semelhante carga de trabalho intelectual, esforço físico, privação de sono, de repouso e má alimentação, poderiam acarretar agravos à saúde. Mas essa afirmação é especialmente verdadeira quando as pessoas em foco estão na adolescência, uma fase especial do desenvolvimento.

Ao longo da presente pesquisa foi possível concluir que, para os alunos, ingressar em uma escola pública de qualidade é adentrar um território estranho e por vezes distante de suas referências. A escola tem desde estudantes muito pobres, de pais com ensino fundamental incompleto, até alunos de classe média alta, com pais doutores. Da entrada à permanência, a vida escolar é um difícil desafio para os que tem uma baixa renda familiar. Alguns deles contrariam a tendência de fracasso "esperada" pelo contexto desfavorável e constroem suas trajetórias com êxito, mas com grande perda da qualidade de vida.

Diante da evidência no discurso de todos os adolescentes e jovens pesquisados, de todas as séries do ensino médio, entre 15 e 18 anos de idade, sobre a falta de tempo efetivo para o sono, é importante apresentar resumidamente alguns resultados de pesquisas sobre o assunto. Para Seixas (2009), a má qualidade do sono pode ter efeitos negativos sobre o desenvolvimento físico, emocional e comportamental dos adolescentes. Mathias, Sanchez e Andrade (2006) encontraram relação entre o baixo rendimento acadêmico associado a horário de sono irregular, níveis de sonolência durante o dia e também horários de dormir tardios. 
Sem dúvida, todos os alunos pesquisados dormem bem menos do que gostariam e necessitariam. Todos, sem exceção, descreveram se como estando sempre cansados ou "completamente exaustos". Eles descrevem suas atividades como estressantes e alguns se declaram estressados. Para Kristensen, Schaefer \& Busnello (2010) o estresse se amplia quando as tensões diárias se mostram mais elevadas que a habilidade do indivíduo em lidar com elas, e o impossibilita de criar novas estratégias, o que, além de reduzir sua qualidade de vida, diminui sua motivação. Ou seja, ele é prejudicial para o estudo e para o desenvolvimento. A atitude apática de alguns alunos em sala de aula e a prática de dormir em quase qualquer lugar da escola, e mesmo em pé nos coletivos, são comuns.

Pelo fato de passarem o dia inteiro na escola, esses adolescentes e jovens não têm tempo livre para outras atividades. Falta-Ihes vitalidade até mesmo para as tarefas comuns do cotidiano. Não fazem exercícios nem esportes, tem pouco contato com amigos e familiares, raramente viajam ou passeiam e relatam raros momentos de lazer e de vida cultural.

A partir da escuta e da observação os estudantes relataram um cotidiano de filas, esperas e desgaste imenso, de problemas emocionais e de aprendizagem. Revelou-se, por exemplo, que não é raro os bolsistas usarem o dinheiro do auxílio oferecido pela escola para ajudar nas despesas da casa. Há também os que, para ter uma renda extra, fazem alguns trabalhos informais, os chamados "bicos". Vieram à tona casos como o das alunas que preparavam doces para vender na escola. Outros, com mais facilidade nas disciplinas da área de exatas, cobravam valores simbólicos para dar aulas particulares. Soube-se, também, de casos de alunos que desmaiaram ao longo do dia pelas duras condições relatadas. Os projetos institucionais de apoio, pode-se inferir, são insuficientes para suprir as demandas, pois atendem apenas a uma parcela dos estudantes.

A falta de tempo sempre apontada pelos alunos, mostra outros aspectos da vida dos estudantes. Percebeu-se uma escola com altas exigên712 cias acadêmicas, mas que não considera as dife- renças sociais; que mantém uma verticalidade quase formal nas relações entre os professores e gestores e o corpo discente, além da centralidade adultocêntrica das decisões, com pouca abertura para o diálogo e a participação dos mais jovens. É um funcionamento pautado nas necessidades e conveniências dos dirigentes - como fica claro nos horários longos, estabelecidos apenas pelos professores e pela direção.

Alguns dos jovens percebem com clareza o campo de contradições entre a ideia de público e democrático e suas severas dificuldades de acesso e permanência - como também acontece com outros jovens brasileiros pobres, em espaços historicamente não destinados a eles (Barbosa, Silva, \& Souza, 2010; Lopes \& Braga, 2007; Zamora \& Larrubia, 2013). Os estudantes mostraram perceber a reprodução das desigualdades existentes no país, espelhadas, em grande medida, na lógica institucional predominante. Desigualdade entre os alunos, entre alunos e professores, burocracia, pouca participação política, invisibilidade dos mais pobres, indiferença dos que tem mais poder... ou, na fala irônica de uma das participantes: "É um mini-Brasil".

A desigualdade social é um dos aspectos perversos de uma política neoliberal e tem seus efeitos no direito à educação pública. Essas são questões para a Educação, a Psicologia e outros saberes afins, pois situações de desigualdade produzidas fora da escola acabam por reforçar contextos de precariedades no interior desta, como mostram os resultados desta pesquisa. Diante desse rol de dificuldades, um dos estudantes comparou a instituição a um "mini-Brasil". Alguns alunos percebem com clareza a reprodução das desigualdades existentes no país como parte da lógica institucional.

Os participantes falaram do cotidiano de filas e esperas, do extremo cansaço, apesar de sua juventude, dos poucos recursos para alimentação e transporte. Esses fatores se somam a problemas emocionais, falta de vocação e/ou informação para o curso técnico escolhido e problemas de aprendizagem. Foi possível inferir que os projetos institucionais são insuficientes para suprir as demandas, pois atendem apenas a uma parcela dos estudantes que necessitam de suporte. O próprio fato de não 
ter sido possível realizar grupos focais e encontros mais demorados com eles, sem exercer um autoritarismo indesejável, por absoluta falta de tempo livre, já é um termômetro da situação real do estudante.

É imprescindível criar novas e múltiplas formas de apoio a estudantes de classes populares, levando em consideração o compromisso social das instituições públicas de educação. Toda comunidade escolar deveria conhecer e ser sensível aos problemas que afligem seus estudantes, a fim de criar estratégias institucionais para a garantia da permanência em condições saudáveis. Essas estratégias precisariam ser criadas com a mais ampla participação, através da auto-análise e da autogestão, ou seja, a partir das potencialidades dos coletivos de identificar seus próprios problemas e, partindo deles, pensar e propor as soluções.

A Psicologia, em seu exercício junto às instituições escolares, cumpre sempre um papel político. É mister a ampliação e o aprimoramento das ações institucionais que intervenham para garantir a inserção de políticas de acesso e permanência, que superem o caráter meritocrático e promovam um espaço acadêmico mais democrático, aumentando as oportunidades de estudar. Este é um desafio que se coloca para toda a comunidade escolar exigindo maior empenho de gestores e servidores na discussão e procura de soluções coletivas. É preciso trazer um olhar crítico para fomentar a consciência do papel político que exercem as instituições escolares, propondo a desnaturalização das desigualdades sociais e educacionais, auxiliando assim a constituição de sujeitos mais conscientes e autônomos. Urge ampliar as discussões sobre uma educação popular comprometida com a emancipação humana.

\section{Referências}

Barbosa, J. L., Silva, S. J ., \& Souza, A. I. (Orgs.). (2010). Acesso e permanência de estudantes de origem popular: desafios e estratégias. Rio de Janeiro: UFRJ.

Bardin, L. (2006). Análise de conteúdo ( $2^{\mathrm{a}}$ ed.). Lisboa: Edições 70.

Baremblitt, G. F. (2002). Compêndio de análise institucional e outras correntes: teoria e prática ( $5^{\text {a }}$ ed.). Belo Horizonte: Instituto Felix Guattari.
Buarque, C. (1999). O que é apartação: o apartheid social no Brasil. São Paulo: Brasiliense.

Campos, M. M. (2003). Educação e políticas de combate a pobreza. Revista Brasileira de Educação, 24, 183-191.

Castel, R. (1998). As metamorfoses da questão social: uma crônica do salário. Petrópolis: Vozes.

Chizzotti, A. (2006). Pesquisa em ciências humanas e sociais. São Paulo: Cortez.

Conceição, V. L. (2012). Psicologia, desigualdade e permanência de alunos em escola profissional técnica de nível médio (Dissertação de mestrado não-publicada). Universidade Salgado de Oliveira, Rio de Janeiro.

Costa, F. B. (2008). Moisés e Nilce: retratos biográficos de dois garis: um estudo de psicologia social a partir de observação participante e entrevistas (Tese de doutorado não-publicada). Universidade de São Paulo. Recuperado em novembro 16, 2011, de http://www. teses.usp.br/teses/disponiveis/47/47134/tde-0901 2009-154159/pt-br.php

Freire, P. (1996). Pedagogia da autonomia. São Paulo: Paz e Terra.

Frigotto, G. (1993). A produtividade da escola improdutiva. Um (re)exame das relações entre educação e estrutura econômico-social capitalista. São Paulo: Cortez.

Gentili, P. (2003). Educar na esperança em tempos de desencanto. Petrópolis: Vozes.

Gonçalves, M. G. (2010). Psicologia, subjetividade e políticas públicas. São Paulo: Cortez.

Gracindo, R. V., Marques, S. C., \& Paiva, O. F. (2005). A contradição exclusão/inclusão na sociedade e na escola. Revista Linhas Críticas, 11(20), 5-25.

Guzzo, R. S. L., \& Euzébios, A. F. (2005). Desigualdade social e sistema educacional brasileiro: a urgência da educação emancipadora. Escritos sobre Educação, 4(2), 39-48. Recuperado em julho 28, 2011, de http:// pepsic.bvsalud.org/scielo.php?script=sci_arttext \&pid=S1677-98432005000200005\&lng=pt\&nrm= iso

Guzzo, R. S. L., \& Lacerda Jr., F. (2009). Psicologia social para a América Latina: o resgate da Psicologia da Libertação. Campinas: Alínea.

Guzzo, R. S. L., Mezzalira, A. S. C., Moreira. A. P. G, Tizzei, R. P., \& Silva Neto, W. M. F. (2010). Psicologia e educação no Brasil: uma visão da história e possibilidades nessa relação. Psicologia: Teoria e Pesquisa, 26(Esp), 131-141.

Kristensen, C. H., Schaefer, L. S., \& Busnello, F. B. (2010). Estratégias de coping e sintomas de stress na adolescência. Estudos de Psicologia (Campinas), 27(1), 21-30. http://dx.doi.org/10.1590/S0103-166X201000 0100003 
Lapassade, G. (2006). La methode ethographique. Introduction Le travail de terrain (fieldwork). Recupéré le mai 11, 2011, à partir de http://www.ai.univ-paris 8.fr/corpus/lapassade/ethngrin.htm

Lavrador, M. C. C. (2005). Processo de exclusão e inclusão social. In M. E. B. Barros \& M. Abdala (Orgs.), Mundo e sujeito: aspectos subjetivos da globalização (pp.115-127). São Paulo: Paulus.

Leal, G. F. (2009). Exclusão como ruptura de laços sociais: uma crítica do conceito. Mediações, 14(1), 260-274.

Lopes, M. A., \& Braga, L. S. (Orgs.). (2007). Acesso e permanência da população negra no ensino superior. Brasília: Ministério da Educação.

Lopes, R. E., Adorno, R. C. F., Malfitano, A. P. S., Takeiti, B. A., Silva, C. R., \& Borba, P. L. O. (2008). Juventude pobre, violência e cidadania. Saúde e Cidadania, 17(3), 63-76.

Lourau, R. (1993). Análise institucional e práticas de pesquisa. Rio de Janeiro: UERJ.

Mathias, A., Sanchez, R. P., \& Andrade, M. M. M. (2006). Incentivar hábitos de sono adequados: um desafio para os educadores. São Paulo: Núcleo de Ensino da Unesp.

Martín-Baró, I. (1986). Hacia uma psicologia de la libertación. Boletim de Psicologia, 22, 219-231.

Martin-Baró, I. (2003). Poder, ideologia y violência. Madrid: Trotta.

Mayorga, C., Pereira, M. S., \& Rasera, E. F. (2009). Psicologia Social: sobre desigualdades e enfrentamentos. Curitiba: Juruá.

Mendes, M. S. (2013). Da inclusão à evasão escolar: o papel da motivação no ensino médio. Estudos de Psicologia (Campinas), 30(2), 261-265. http://dx.doi.org/ 10.1590/S0103-166X2013000200012

Neves, L. M. (2005). Educação e política no Brasil de hoje. São Paulo: Cortez.

Neves, V. F. A. (2006). Pesquisa e etnografia: caminhos cruzados. Pesquisa e Práticas Psicossociais, 1(1), 1-17.

Patto, M. H. S. (1999). A produção do fracasso escolar: histórias de submissão e rebeldia. São Paulo: Casa do Psicólogo.
Penteado, Z., \& Guzzo, R. S. L. (2010). Educação e Psicologia: a construção de um projeto político-pedagógico emancipador. Psicologia \& Sociedade, 22(3), 569-577.

Pinho, G. S. A., Ribeiro, H. B. A., \& Souza, R. R. (2009). Quem cabe na escola? Instituições de ensino e as práticas de exclusão. Mnemosine, 5(2), 249-259.

Programa das Nações Unidas para o Desenvolvimento. (2011). Relatório do Desenvolvimento Humano 2011. Recuperado em julho 6, 2015 de www.pnud.org.br/ hdr/arquivos/RDHglobais/hdr_2011_pt_complete.pdf

Ramos, A. C., Rocha, M. L., Pimenta, T. J., \& Breia, V. C. (2004). O psicólogo na escola: história e formação. In A. M. Jacó-Vilela, F. Jabur, \& H. B. C. Rodrigues (Orgs.), Clio-psyché: histórias da Psicologia no Brasil. Rio de Janeiro: UERJ.

Rocha, M. L., \& Aguiar, K. F. (2003). Pesquisa-intervenção e a produção de novas análises. Psicologia: Ciência e Profissão, 23(4), 64-73.

Sawaia, B. B. (2009). Psicologia e desigualdade social: uma reflexão sobre a liberdade e transformação social. Psicologia e Sociedade, 3(21), 364-372.

Seixas, M. P. (2009). Avaliação da qualidade do sono na adolescência: implicações para a saúde física e mental (Dissertação de mestrado não-publicada). Universidade Fernando Pessoa, Portugal.

Sung, J. M. (2002). Sujeito e sociedades complexas: para repensar os horizontes utópicos. Petrópolis: Vozes.

Therborn, G. (2010). Os campos de extermínio da desigualdade. São Paulo: Novos estudos.

Thiollent, M. (2000). Metodologia da pesquisa-ação. São Paulo: Cortez.

Zamora, M. H., \& Larrubia, B. (2013) L'université brésilienne, travail, inégalités sociales: anciens et nouveaux défis. In M. Diakhaté (Org.), Formation et insertion professionnelle. Paris: Paris VIII.

Recebido: março 7, 2013

Versão final: dezembro 17, 2013

Aprovado: janeiro 30, 2014 